\title{
Obituary
}

\section{Professor Norman Farnsworth Dies at 81}

\section{I.E.Cock ${ }^{\text {ab* }}$}

${ }^{a}$ Biomolecular and Physical Sciences, Nathan Campus, Griffith University, 170 Kessels Rd, Nathan, Brisbane, Queensland 4111, Australia. ${ }^{b}$ Environmental Futures Centre, Nathan Campus, Griffith University, 170 Kessels Rd, Nathan, Brisbane, Queensland 4111, Australia.

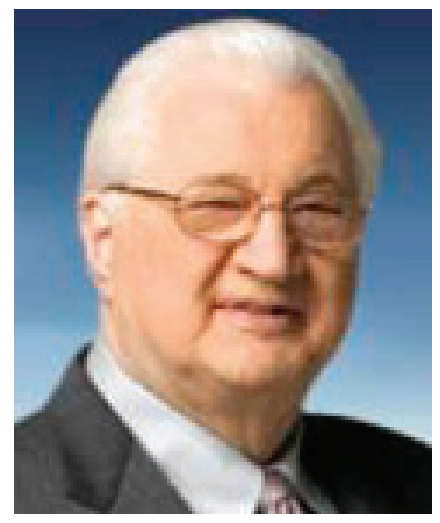

Prof. Norman R. Farnsworth, a renowned medicinal plant researcher and a giant in the field of pharmacognosy, died September 12, 2011 in Chicago. Dr Farnsworth graduated with a degree in pharmacy from Massachusetts College of Pharmacy in 1953. He subsequently undertook postgraduate studies in pharmacognosy at the University of Pittsburgh, receiving his $\mathrm{PhD}$ in 1959. He was instrumental in instituting a pharmacognosy $\mathrm{PhD}$ program at the University of Pittsburgh and was its inaugural chair. In 1970, Prof. Farnsworth accepted a post in the College of Pharmacy at the University of Illinois, Chicago, serving as Departmental Head from 1970-1982. In this role he mentored more than $100 \mathrm{PhD}$ students, $30 \mathrm{MS}$ students and 30 postdoctoral fellows.

Prof Farnsworth was a leading researcher in pharmacognosy, publishing hundreds of research papers in peer reviewed international journals. Furthermore, he co-founded the journals Phytomedicine and the International Journal of
Phytotherapy and Phytopharmacology. His many other achievements include:

- founding member of the American Society of Pharmacognosy (ASP) (1959).

- founding member of the American Society of Economic Botany (1959).

- creation of the Natural Products Alert (NAPralert) database at the University of Illinois.

- Principal Investigator and Director of the Botanical Dietary Supplements for Women's Health Centre, the University of Illinois.

- co-founder of the American Botanical Council (ABC) and a long serving member of its board of trustees.

- recipient of numerous international awards including the SEB's Distinguished Economic Botanist Award in 1983.

- member on the Commission on Dietary Supplements Labels, a commission established to develop recommendations for the review of quality, safety, benefits and labelling of dietary supplements.

Prof Farnsworth has been an inspiration to many of us in the field of pharmacognosy and will be especially missed by his family and the numerous colleagues who have been fortunate in knowing this giant of pharmacognosy. 